\title{
Reliability, factor structure, and validity of the Inventory of Complicated Grief (ICG) in a general bereaved sample in Norway
}

psykologisk.no/sp/2019/05/e7

The findings of this study suggest that the Norwegian Inventory of Complicated Grief has good reliability and adequate factorial validity, write Jens $\mathrm{C}$. Thimm and colleagues.

BY: Jens C. Thimm, Maylinn Davidsen, Mie M. Elsness and Helga Vara

The loss of a loved one to death and grief processes is a nearly universal experience. A number of bereaved individuals experience intense grief reactions that last longer than would be expected based on social, cultural, and religious norms and that cause significant distress and impairment in personal, social, or occupational function (Shear, 2015). These reactions have been termed differently, including (but not limited to) complicated grief (CG; Shear et al., 2011), prolonged grief disorder (Maercker et al., 2013; Prigerson et al., 2009), and persistent complex bereavement disorder (American Psychiatric Association, 2013). CG is characterized by intense yearning for the deceased and strong emotional pain, including sadness, anger, guilt, confusion about one's role in life, and difficulties accepting the loss and moving on in life (Shear, 2015). A population-based study in Germany found a prevalence of CG of $3.7 \%$ in the general population (Kersting, Brähler, Glaesmer, \& Wagner, 2011). For bereaved populations, a recent metaanalysis reported a prevalence of $9.8 \%$ (Lundorff, Holmgren, Zachariae, Farver-Vestergaard, \& O'Connor, 2017). Several factors, such as loss due to violent death, close relation to the deceased, and lack of social support can increase the individual's risk of developing CG (Burke \& Neimeyer, 2013). CG is highly comorbid with psychiatric disorders, especially depression and posttraumatic stress disorder (PTSD) ( al., 2007), which increases the risk of misdiagnosing patients with CG. However, research has demonstrated that CG is a syndrome that is distinct from depression and PTSD (e.g., Boelen, van de Schoot, van den Hout, de Keijser, \& van den Bout, 2010; Golden \& Dalgleish, 2010). For an overview of clinical characteristics that distinguish CG from depression and 
PTSD, see Shear (2015). Importantly, CG has been found to predict suicidal ideation and actions beyond depression and PTSD (Latham, \& Prigerson, 2004). It has also been demonstrated that evidence-based treatment for depression is less effective for individuals with CG than treatment for $C G$ is (Shear, Frank, Houck, \& Reynolds, 2005; Shear, Wang, Skritskaya, Duan, Mauro, \& Ghesquiere, 2014). Thus, the assessment of CG is crucial, particularly in individuals who are depressed and/or have experienced trauma (Klinitzke, Domschke, Wagner, Klauke, \& Kersting, 2014; Nickerson, Liddell, Maccallum, Steel, Silove, \& Bryant, 2014). For example, there is an increasing recognition of the importance of CG reactions to refugees, most of whom have experienced multiple losses in addition to the violent loss of loved ones, including the loss of their homes, work, and social networks (Silove, Ventevogel, \& Rees, 2017).

A number of instruments have been developed for the assessment of grief reactions. (For reviews, see Neimeyer, Hogan, \& Laurie, 2008, and Neimeyer, 2017.) The Inventory of Complicated Grief (ICG; Prigerson Maciejewski, et al., 1995) is currently the most widely used instrument to assess symptoms of CG. The ICG is a self-report inventory developed to aid the discrimination between usual and complicated grief. The ICG comprises 19 items covering symptoms of grief that in a preceding study had shown themselves to be distinct from depression and anxiety (Prigerson, Frank, et al., 1995). In addition, grief-related items based on clinical experience regarding characteristics of maladaptive grief responses were included. As an overall strategy, items were selected to yield a unidimensional model of CG (Prigerson, Maciejewski, et al., 1995). In a sample of 97 widowed elderly (Prigerson, Maciejewski, et al., 1995), an exploratory factor analysis supported one underlying factor. Cronbach's alpha of the ICG total score was .94. The test-retest reliability over a six-month period was .80. The correlations with the Beck Depression Inventory (Beck, Ward, Mendelson, Mock, \& Erbaugh, 1961) and the Texas Revised Inventory of Grief (Faschingbauer, Zisook, \& DeVaul, 1987) were .67 and .87, respectively. In the construction sample, participants with ICG scores higher than 25 (representing $20 \%$ of the sample) were found to have significantly poorer mental and physical health and lower social functioning than the participants scoring below this threshold. Hence, Prigerson, Maciejewski, et al. (1995) recommended a 
cutoff score of $>25$ to distinguish between uncomplicated and complicated grief reactions. In some studies, a cutoff point of $\geq$ 30 for the ICG total score is applied (e.g., Shear et al., 2005). However, the empirical basis for this cutoff point is unclear.

Subsequent studies on the factor structure of the ICG have diverged in their findings: several studies have concluded with one underlying dimension (Carmassi et al., 2014; Han et al., 2016; Lumbeck, Brandstatter, \& Geissner, 2012; Prigerson, Maciejewski, et al., 1995). Masferrer, Garre-Olmo, \& Caparros (2017) reported four factors (discomfort, non-acceptance, loneliness/isolation, and presence of deceased). Simon et al. (2011) found one factor in their full bereaved sample and six factors in the group of participants diagnosed with CG (yearning and preoccupation with the deceased, anger and bitterness, shock and disbelief, estrangement from others, hallucinations of the deceased, and behavior change). Fisher et al. (2017) replicated five of the six factors of the Simon et al. (2011) study, all except for behavior change.

The ICG has been used in different areas of grief research. For example, the ICG has been employed to investigate the prevalence of $C G$ in individuals in different bereavement groups (e.g., Dyregrov, Nordanger, \& Dyregrov, 2003; Li, Chow, Shi, \& Chan, 2015; Newson, Boelen, Hek, Hofman, \& Tiemeier, 2011), to evaluate the outcome of grief-targeted treatments (e.g., Barbosa, Sa, \& Rocha, 2014; Shear et al., 2014), or to examine correlates of CG (e.g., Arizmendi, Kaszniak, \& O'Connor, 2016; Fernandez-Alcantara et al., 2016; Zetumer et al., 2015).

The psychometrics of translations of the ICG have been reported for some languages (e.g., Carmassi et al., 2014; Han et al., 2016; Lumbeck et al., 2012; Masferrer et al., 2017). The Norwegian version of the ICG has been used in several studies (e.g., Dyregrov, Dyregrov, \& Kristensen, 2015; Dyregrov et al., 2003; Kristensen, Weisæth, Hussain, \& Heir, 2015). However, a psychometric investigation of the ICG has not yet been undertaken in a Norwegian population. The purpose of the present study was to examine the reliability and factor structure of the Norwegian ICG. Further, the study aimed to explore the construct validity of the ICG by testing its relationships with symptoms of depression and anxiety, meaning made of the loss, and functional impairment.

Material and methods 


\section{Participants}

The data used in the present investigation were compiled from three studies at the Department of Psychology at the University of Tromsø. The results of one of these studies have been published (Thimm \& Holland, 2017). Participants in the three studies were recruited by email invitations sent to university students and employees at a local educational institution and via social media posts containing a link to an online survey. They responded anonymously to the study measures. Individuals grieving the loss of a loved one to death were invited to participate. There were no exclusion criteria. On the first page of the surveys, participants were informed about the purpose of the study, the researchers and how to contact them, the estimated time needed to complete the survey, voluntary and anonymous participation, and how to provide electronic consent (by completing and submitting the questionnaire in one study and by agreeing to an informed consent statement in two studies). Because no personally identifiable information was collected (including email or IP addresses), approval from the Regional Committee for Medical and Health Research Ethics was not required according to the Norwegian Health Research Act. In addition, the supplier of the online surveys (Questback) had no access to email addresses and IP addresses. Therefore, notification of the Norwegian Centre for Research Data was not required.

Since the number of bereaved who were reached by the invitation to participate is unknown, the response rate could not be determined. Participants grieving the loss of a pet or reporting multiple losses $(n=11)$ were excluded from the analyses. The final sample comprised 490 bereaved individuals. The participants' mean age was 34.3 years $(S D=$ 13.7 years), and $81 \%$ were female. On average, 90.7 months had passed since the death $(S D=101.8$, data from 22 participants were missing on this variable). The mean age of the deceased was 52 years ( $S D=25.5$ years, one missing data point). Of the participants, $30.2 \%$ were grieving the loss of a grandparent, $29.8 \%$ a parent, $16.1 \%$ a friend, $6.9 \%$ a sibling, $5.9 \%$ a partner, $5.1 \%$ another relative, $2.7 \%$ a child, and $3.3 \%$ another person. The cause of death was natural expected (40.4\%), natural sudden $(28.2 \%)$, unnatural sudden $(25.1 \%)$, and other $(6.3 \%)$.

\section{Measures}


Inventory of Complicated Grief (ICG). As described above, the ICG is a 19-item self-report measure developed to assess complicated grief. Items are answered on a five-point frequency scale ranging from 0 (never) to 4 (always). The ICG was translated into Norwegian in the late 1990s by Atle Dyregrov in cooperation with the scale developer (A. Dyregrov, personal communication, February 19, 2019). The Norwegian ICG has subsequently been used in several published studies (e.g., Dyregrov et al., 2015; Dyregrov et al., 2003; Kristensen et al., $\underline{2015})$.

Brief Symptom Inventory (BSI). Symptoms of depression and anxiety were assessed with the respective six-item scales of the BSI (Derogatis, 1992). Items are scored on a five-point Likert scale from 0 (not at all) to 4 (extremely). In the present sample, the reliability coefficient omega total $\left(\omega_{t}\right)$ was .92 for depression and .94 for anxiety, respectively. For 152 participants, the BSI depression scale was extracted from the depression scale of the Symptom Checklist 90-R (Derogatis, 2010). For all participants, data from the BSI depression scale were available, and 338 participants answered the BSI anxiety scale. Items were taken from the official Norwegian translation of the SCL-90-R (Derogatis, 2010).

Integration of Stressful Life Events Scale - Short Form (ISLESSF). The ISLES-SF (Holland, Currier, \& Neimeyer, 2014) is an abbreviated form of the 16-item ISLES (Holland, Currier, Coleman, \& Neimeyer, 2010) and consists of six items that are scored on a five-point scale from 1 (strongly agree) to 5 (strongly disagree). The ISLES/ISLES-SF assesses meaning made after a stressful life event (e.g., "The loss is incomprehensible to me."). Lack of integration has shown to be highly correlated with symptoms of CG (Holland et al., 2010). The ISLES was translated into Norwegian using the translationbacktranslation method (Thimm \& Holland, 2017). The ISLES was administered to 151 participants, and the items of the ISLES-SF were extracted from the full form for these participants. The ISLES-SF was completed by 187 participants. In the current study, the ISLES-SF had a reliability $\left(\omega_{t}\right)$ of .95 .

Work and Social Adjustment Scale (WSAS). The WSAS (Mundt, Marks, Shear, \& Greist, 2002) is a widely used five-item scale designed to assess functional impairment in connection with mental disorders. Items are rated on a nine-point Likert scale from 0 (not at all) to 8 (severely impaired). The WSAS 
was administered to 187 participants. In the present study, the scale had an $\omega_{t}$ of .96 . The WSAS has previously been used in published studies in Norway (e.g., Dyregrov et al., 2015;

Pedersen, Kvarstein, \& Wilberg, 2017). Unfortunately, information about the translation of the WSAS into Norwegian is not provided in these publications.

\section{Analyses}

Descriptives of the sample and the ICG and correlations of the ICG with the depression and anxiety subscales of the BSI, the ISLES-SF, and the WSAS were calculated in SPSS 24 . The psych package 1.7.5 (Revelle, 2017) was used in R 3.4.1 to compute item-total correlations and the reliability coefficient $\omega_{t}$ and to test differences between correlations. To determine the number of factors to be extracted in the exploratory factor analysis (EFA) of the ICG items, parallel analysis and Velicer's Minimum Average Partial (MAP) test (Horn, 1965) was conducted using O'Connor's (2000) SPSS macro. The EFA was performed in Mplus 7.4 (Muthén \& Muthén, 1998-2012) with weighted least square mean and variance (WLSMV) estimation and oblique CF-Equamax rotation. CF-Equamax rotation was chosen because it aims at simplifying variable and factor complexity by spreading variances equally across the factors (Browne, 2001; Schmitt \& Sass, 2011). Model fit was evaluated with the root mean square error of approximation (RMSEA), the comparative fit index (CFI), and the Tucker Lewis index (TLI). Omega hierarchical $\left(\omega_{h}\right)$ was calculated using the psych package to estimate the proportion of variance that is explained by the general factor in a bifactor model. Reise, Bonifay, and Haviland (2013) suggest that $\omega_{h}$ should be at least .50 and preferably be closer to .75 to justify the use of a total score in multidimensional scales. Finally, tests of the differences between the ICG factors and the depression and anxiety subscales of the BSI, the ISLES-SF, and the WSAS (Steiger Tests) were conducted in the psych package.

\section{Results}

In the current sample, the ICG total score had a mean of 21.72 $(S D=12.86)$. The mean scores of the ICG items and the proportion of endorsement (i.e., experiencing a given symptom at least sometimes) are displayed in Table 1. The items that had the highest means and that were most frequently endorsed were longing for the deceased $(M=2.57,87 \%)$ and feeling drawn to places associated with the deceased $(M=1.73,59 \%)$. 
The least frequently endorsed symptoms were having lost the ability to care about other people $(M=0.53,14 \%)$, feeling that it is unfair that one should live when the other person died $(M=$ $0.53,15 \%)$, avoiding reminders of the deceased $(M=0.53$, $16 \%)$, and difficulties trusting other people $(M=0.57,16 \%)$. The reliability coefficient $\omega_{t}$ was .95 . Item-total correlations are also shown in Table 1 and ranged from .40 (item 15) to .72 (item 13).

TABLE 1: Descriptives of ICG items and factor loadings after EFA with CF-Equamax rotation.

\begin{tabular}{|c|c|c|c|c|c|c|}
\hline \multirow[b]{2}{*}{ ICG items (item \#) } & \multirow{2}{*}{$\begin{array}{l}\mathrm{M} \\
(\mathrm{SD})\end{array}$} & \multirow{2}{*}{$\begin{array}{l}\text { Item- } \\
\text { total } \\
\text { corr. }\end{array}$} & \multirow{2}{*}{$\begin{array}{l}\text { Proportion } \\
\text { endorsed }\end{array}$} & \multicolumn{3}{|c|}{ Factor loadings after EFA } \\
\hline & & & & $\begin{array}{l}\text { Disbelief/ } \\
\text { bitterness }\end{array}$ & Detachment & $\begin{array}{c}\text { Yearning/ } \\
\text { hallucinations }\end{array}$ \\
\hline I feel disbelief over what happened. (7) & $\begin{array}{l}1.22 \\
(1.23)\end{array}$ & .65 & .40 & .86 & -.02 & .03 \\
\hline $\begin{array}{l}\text { I can't help feeling angry about his/her } \\
\text { death. (6) }\end{array}$ & $\begin{array}{c}1.21 \\
(1.18)\end{array}$ & .65 & .38 & .76 & .12 & -.02 \\
\hline $\begin{array}{l}\text { I feel bitter over this person's death. } \\
\text { (17) }\end{array}$ & $\begin{array}{l}1.02 \\
(1.20)\end{array}$ & .71 & .23 & .75 & .23 & -.03 \\
\hline $\begin{array}{l}\text { I feel stunned or dazed over what } \\
\text { happened. (8) }\end{array}$ & $\begin{array}{c}0.98 \\
(1.11)\end{array}$ & .67 & .28 & .68 & .10 & .15 \\
\hline $\begin{array}{l}\text { I feel I cannot accept the death of the } \\
\text { person who died. (3) }\end{array}$ & $\begin{array}{l}1.36 \\
(1.21)\end{array}$ & .68 & .45 & .66 & .01 & .24 \\
\hline $\begin{array}{l}\text { Memories of the person who died upset } \\
\text { me. (2) }\end{array}$ & $\begin{array}{r}1.23 \\
(1.04)\end{array}$ & .65 & .39 & .37 & .33 & .19 \\
\hline $\begin{array}{l}\text { Ever since s/he died it is hard for me to } \\
\text { trust people. (9) }\end{array}$ & $\begin{array}{l}0.57 \\
(0.98)\end{array}$ & .57 & .16 & .15 & .81 & -.10 \\
\hline Ever since s/he died I feel like I have & & & & & & \\
\hline $\begin{array}{l}\text { lost the ability to care about other } \\
\text { people or I feel distant from people I } \\
\text { care about. (10) }\end{array}$ & $\begin{array}{l}0.53 \\
(0.92)\end{array}$ & .53 & .14 & .03 & .79 & -.01 \\
\hline $\begin{array}{l}\text { I feel lonely a great deal of the time ever } \\
\text { since s/he died. (19) }\end{array}$ & $\begin{array}{c}0.99 \\
(1.07)\end{array}$ & .70 & .30 & .06 & .58 & .36 \\
\hline $\begin{array}{l}\text { I go out of my way to avoid reminders of } \\
\text { the person who died. (12) }\end{array}$ & $\begin{array}{c}0.53 \\
(0.87)\end{array}$ & .49 & .16 & .23 & .46 & .07 \\
\hline I have pain in my body. (11) & $\begin{array}{c}0.88 \\
(1.08)\end{array}$ & .56 & .26 & .04 & .45 & .32 \\
\hline $\begin{array}{l}\text { I feel that it is unfair that I should live } \\
\text { when this person died. (16) }\end{array}$ & $\begin{array}{l}0.53 \\
(0.96)\end{array}$ & .51 & .15 & .24 & .42 & .15 \\
\hline $\begin{array}{l}\text { I feel envious of others who have not } \\
\text { lost someone close. (18) }\end{array}$ & $\begin{array}{c}1.26 \\
(1.38)\end{array}$ & .54 & .27 & .19 & .39 & .18 \\
\hline $\begin{array}{l}\text { I hear the voice of the person who died } \\
\text { speak to me. (14) }\end{array}$ & $\begin{array}{l}0.95 \\
(1.06)\end{array}$ & .50 & .32 & .07 & -.07 & .74 \\
\hline $\begin{array}{l}\text { I see the person who died stand before } \\
\text { me. (15) }\end{array}$ & $\begin{array}{l}1.39 \\
(1.14)\end{array}$ & .40 & .48 & .12 & -.25 & .72 \\
\hline $\begin{array}{l}\text { I feel myself longing for the person who } \\
\text { died. (4) }\end{array}$ & $\begin{array}{r}2.57 \\
(1.01)\end{array}$ & .61 & .87 & .04 & .18 & .67 \\
\hline $\begin{array}{l}\text { I feel drawn to places and things } \\
\text { associated with the person who died. } \\
\text { (5) }\end{array}$ & $\begin{array}{r}1.73 \\
(1.04)\end{array}$ & .48 & .59 & -.05 & .09 & .65 \\
\hline $\begin{array}{l}\text { I feel that life is empty without the } \\
\text { person who died. (13) }\end{array}$ & $\begin{array}{l}1.62 \\
(1.19)\end{array}$ & .72 & .23 & .08 & .32 & .61 \\
\hline I think about this person so much that & 1.14 & & & & & \\
\hline
\end{tabular}


it's hard for me to do the things I

The MAP test and parallel analysis indicated unequivocally extracting three factors from the ICG items. The first four observed eigenvalues were $7.417,1.816,1.361$, and 0.981 . The fourth eigenvalue was lower than one could expect from random data $(1.365,1.293,1.242$, and 1.198). The three-factor solution also showed the lowest average partial correlation. The first four values were $0.024,0.020,0.018$, and 0.021 , respectively. The model with three factors fit the data reasonably well (RMSEA $=.07, \mathrm{CFI}=.97, \mathrm{TLI}=.96)$. The threefactor model showed a better model fit than a model with one factor (RMSEA = .12, CFI = .86, TLI = .84). Comparisons between the three-factor model and the two-factor model and between the two-factor model and the one-factor model showed significant differences, $X^{2}(17)=225.88, p<.001$, and $X^{2}(18)=$ 401.03, $p<.001$, respectively. As shown in Table 1, the first factor was primarily defined by items assessing disbelief and bitterness and labeled disbelief/bitterness accordingly. The second factor was mainly represented by difficulties trusting other people and feeling distant from people one cares about. This factor was labeled detachment. The third factor was labeled yearning/hallucinations and was primarily characterized by items measuring seeing and hearing the deceased and longing for the deceased. Three ICG items showed substantial cross-loadings ( $\geq .30$ ): item 2 (primary loading on disbelief/bitterness) and items 1 and 13 (primary loading on yearning/hallucinations) loaded on detachment. The latent factors showed moderate to high correlations.

Disbelief/bitterness was correlated with detachment $(r=.51)$ and yearning/hallucinations $(r=.38)$. The correlation between detachment and yearning/hallucinations was $r=.34$. The coefficient $\omega_{h}$ was .73 , indicating that $77 \%$ of the reliable variance $\left(\omega_{h}\right.$ divided by $\left.\omega_{t}\right)$ could be attributed to a general factor.

The correlations of the ICG total score and the three ICG factors with depression, anxiety, functional impairment, and integration of the loss are displayed in Table 2, showing moderate to high associations. Significance tests of differences between the correlations of the ICG factors with the validity measures revealed that detachment was more strongly related to depression, anxiety, and functional impairment than 
disbelief/bitterness and yearning/hallucinations. Further, detachment and disbelief/bitterness were more highly correlated with difficulties integrating the loss than yearning/hallucinations (all $p<.01$ ).

TABLE 2: Bivariate correlations of the ICG total score and ICG factors with depression, anxiety, functional impairment, and meaning made.

\begin{tabular}{lcccc}
\hline & $\begin{array}{c}\text { BSI } \\
\text { depression }\end{array}$ & $\begin{array}{c}\text { BSI anxiety } \\
(n=490)\end{array}$ & WSAS & ISLES-SF \\
& .44 & .51 & .61 & -.75 \\
& .34 & .38 & .39 & -.66 \\
ICG Total Score & .45 & .49 & .65 & -.68 \\
ICG Disbelief/Bitterness & .29 & .33 & .41 & -.49 \\
ICG Yearning/Hallucinations & & & & \\
\hline
\end{tabular}

Note. ICG = Inventory of Complicated Grief. BSI = Brief Symptom Inventory. WSAS = Work and Social Adjustment Scale. ISLES-SF = Integration of Stressful Life Events Scale Short Form. All correlations significant at $p<.001$.

\section{Discussion}

The purpose of the current study was to investigate the psychometric properties of the ICG in a Norwegian bereaved sample. To this aim, the reliability, factor structure, and associations of the ICG with depression, anxiety, meaning making, and functional impairment were examined.

Similar to earlier studies on the ICG in non-U.S. samples (e.g., Carmassi et al., 2014; Han et al., 2016; Lumbeck et al., 2012; Masferrer et al., 2017), the Norwegian ICG showed high reliability. Moreover, all items exhibited item-total correlations that are well above the commonly used threshold of .30. The finding that longing for the deceased was the most frequently endorsed item supports the idea that yearning is a core symptom of CG ( Shear, 2015).

Exploratory factor analysis of the ICG items yielded three factors that were labeled disbelief/bitterness, detachment, and yearning/hallucinations, based on the symptoms with the highest loadings on these factors. The three-factor solution had an adequate model fit and overall simple structure with only three items showing substantial cross-loadings. In the present sample, the disbelief and anger/bitterness factors as well as the hallucinations and yearning factors of the Simon et al. (2011) 
and Fisher et al. (2017) studies clustered in one factor each. As in the Fisher et al. (2017) study, the behavior change factor from the Simon et al. (2011) study did not emerge as a separate factor. The two items that defined this factor loaded in the current study on detachment (avoidance of the reminders of the deceased) and yearning/hallucinations (feeling drawn to places associated with the deceased), respectively. Previous studies on the factor structure of the ICG varied greatly in their conclusions, ranging from one (e.g., Lumbeck et al., 2012; Prigerson, Maciejewski, et al., 1995) to six factors (Simon et al., 2011). In these studies, the number of factors extracted was not related to whether the sample was composed of general bereaved individuals or participants diagnosed with CG. For example, Lumbeck et al. (2012) concluded with one factor using a sample of psychosomatic patients with CG, whereas Masferrer et al. (2017) found four factors in a sample of bereaved substance abusers. Rather, decisions made in the factor analytic process may, at least in part, account for the divergent findings. For example, Simon et al. (2011) found in their general bereaved sample three factors with eigenvalues larger than 1 but deemed only the first factor interpretable. Lumbeck et al. (2012) reported that five factors had eigenvalues larger than 1, but relying on the MAP test, they also concluded with one factor. Thus, although the ICG was constructed as a unidimensional measure, findings from several studies, including the current investigation, suggest that CG is a multidimensional construct. However, the results of the present study also indicate that the use of the ICG total score is justified. The index $\omega_{h}(.73)$ was close to the threshold of .75 suggested by Reise et al. (2013), which supports the calculation and interpretation of the total score of the ICG.

The moderate to high correlations of the ICG total score with symptoms of anxiety and depression align with previous findings, demonstrating that CG overlaps with depression and anxiety disorders but is distinguishable from these diagnoses (e.g., Boelen et al., 2010; Simon et al., 2007). The examination of the ICG factors showed that detachment in particular is associated with symptoms of depression and anxiety. This finding is in accordance with research showing that loneliness is an important link between bereavement and depression (e.g., Fried et al. 2015). Further, strong negative associations of the ICG with integration of the loss are in line with cognitivebehavioral (e.g., Boelen, van den Hout, \& van den Bout, 2006) 
and constructivist approaches to CG (Gillies \& Neimeyer, 2006). Therein, a lack of integration is proposed to be central to the understanding of $C G$ reactions, a tendency that replicates previous empirical findings (e.g., Boelen, 2010; Holland et al., 2010). Finally, the high correlation of the ICG with the WSAS underscores the functional impairment that is associated with CG. Taken together, in the current study, the Norwegian ICG showed good external validity.

The current study has several limitations that have to be taken into account when interpreting the results. In this investigation, a convenient sample of bereaved individuals has been used, which is not representative of the total population of such individuals. Due to the non-clinical nature of the sample, range restriction and reduced variances may have affected the covariances and correlations the factor analysis are based on. Given the importance of culture for the experience and expression of grief (Granek \& Peleg-Sagy; 2017; Rosenblatt, 2008), a shortcoming of the present investigation is that information about the participants' ethnicity was not obtained. In addition, participants were predominantly female (81\%).

Previous studies on the psychometrics of the ICG had similar gender distributions (e.g., Fisher et al., 2017; Lumbeck et al.. 2012), which supports the comparison of these studies with the present investigation. On the other hand, gender differences in grief reactions to bereavement are well documented (e.g., Stroebe, Stroebe, \& Schut, 2001), and the generalizability of the current findings to men is unclear. Further, participants with different types of bereavement with respect to cause of death (e.g., natural vs. violent) and relationship to the deceased were pooled in the analyses. However, these factors have shown to affect the profile of grief reactions after a loss (FernándezAlcántara \& Zech, 2017; Kristensen, Weisæth, \& Heir, 2012). Future studies should examine the measurement invariance of the ICG across gender, age, ethnicity, cause of death, and relationship to the deceased. There is also a need for more research into determining the ICG cut-off point to identify CG cases. The threshold of $>25$ recommended by Prigerson, Maciejewski, et al. (1995) is based on a small and homogenous sample of widowed elderly individuals and warrants validation in other groups of bereaved.

Conclusion

In conclusion, the findings of the present study suggest that the Norwegian ICG has good reliability and adequate factorial 
validity. A factor analysis of the ICG items yielded three factors that align with previous findings. The Norwegian ICG showed external validity with respect to associations with depression, anxiety, meaning made of the loss, and functional impairment. The results of the current investigation support the use of the ICG in bereaved populations in Norway.

\section{References}

American Psychiatric Association (2013). Diagnostic and Statistical Manual of Mental Disorders (5th ed.). Washington: Author.

Arizmendi, B., Kaszniak, A. W., \& O'Connor, M. F. (2016). Disrupted prefrontal activity during emotion processing in complicated grief: An FMRI investigation. Neuroimage, 124, 968-976. doi:10.1016/j.neuroimage.2015.09.054

Barbosa, V., Sa, M., \& Rocha, J. C. (2014). Randomised controlled trial of a cognitive narrative intervention for complicated grief in widowhood. Aging \& Mental Health, 18, 354-362. doi:10.1080/13607863.2013.833164

Beck, A. T., Ward, C. H., Mendelson, M. M., Mock, J. J., \& Erbaugh, J. J. (1961). An inventory for measuring depression. Archives of General Psychiatry, 4, 561-571. doi:10.1001/archpsyc.1961.01710120031004

Boelen, P. A. (2010). A sense of 'unrealness' about the death of a loved-one: An exploratory study of its role in emotional complications among bereaved individuals. Applied Cognitive Psychology, 24, 238-251. doi:10.1002/acp.1557

Boelen, P. A., van den Bout, J., \& van den Hout, M. A. (2006). Negative cognitions and avoidance in emotional problems after bereavement: A prospective study. Behaviour Research and Therapy, 44, 1657-1672. doi:10.1016/j.brat.2005.12.006

Boelen, P. A., van de Schoot, R., van den Hout, M. A., de Keijser, J., \& van den Bout, J. (2010). Prolonged grief disorder, depression, and posttraumatic stress disorder are distinguishable syndromes. Journal of Affective Disorders, 125, 374-378. doi:10.1016/j.jad.2010.01.076

Browne, M. W. (2001). An overview of analytic rotation in exploratory factor analysis. Multivariate Behavioral Research, 36, 111-150. doi:10.1207/S15327906MBR3601 05 
Burke, L. A., \& Neimeyer, R. A. (2013). Prospective risk factors for complicated grief: A review of the empirical literature. In M. Stroebe, H. Schut, \& J. Van den Bout (Eds.), Complicated Grief: Scientific Foundations for Health Care Professionals (pp. 145-161). East Sussex: Routledge.

Carmassi, C., Shear, M. K., Massimetti, G., Wall, M., Mauro, C., Gemignani, S., . . Dell'Osso, L. (2014). Validation of the Italian version Inventory of Complicated Grief (ICG): A study comparing CG patients versus bipolar disorder, PTSD and healthy controls. Comprehensive Psychiatry, 55, 1322-1329. doi:10.1016/i.comppsych.2014.03.001

Derogatis, L. R. (1992). BSI - Administration, Scoring, and Procedures Manual II. Baltimore: Clinical Psychometric Research.

Derogatis, L. R. (2010). Symptom Checklist-90-R: Norsk Versjon. Stockholm: Pearson Assessment.

Dyregrov, K., Dyregrov, A., \& Kristensen, P. (2015). Traumatic bereavement and terror: The psychosocial impact on parents and siblings 1.5 years after the July 2011 terror killings in Norway. Journal of Loss \& Trauma, 20, 556-576.

doi:10.1080/15325024.2014.957603

Dyregrov, K., Nordanger, D., \& Dyregrov, A. (2003). Predictors of psychosocial distress after suicide, SIDS and accidents. Death Studies, 27, 143-165. doi:10.1080/07481180302892

Faschingbauer, T. R., Zisook, S., and DeVaul, R. (1987). The Texas Revised Inventory of Grief. In: Zisook, S. (Ed.), Biopsychosocial Aspects of Bereavement (pp. 109-124). Washington: American Psychiatric Press.

Fernandez-Alcantara, M., Cruz-Quintana, F., Perez-Marfil, M. N., Catena-Martinez, A., Perez-Garcia, M., \& Turnbull, O. H. (2016). Assessment of emotional experience and emotional recognition in complicated grief. Frontiers in Psychology, 7, 126. doi:10.3389/fpsyg.2016.00126

Fernández-Alcántara, M., \& Zech, E. (2017). One or multiple complicated grief(s)? The role of kinship on grief reactions.

Clinical Psychological Science, 5, 851-857. doi: $\underline{10.1177 / 2167702617707291}$ 
Fisher, J. E., Mauro, C., Cozza, S. J., Wall, M., Simon, N. M., Ortiz, C. D., . . Katherine Shear, M. (2017). Examination of factor structure of the Inventory of Complicated Grief (ICG) in a sample of bereaved military family members with persistent and elevated grief. International Journal of Methods in Psychiatric Research, 26, e1571. doi:10.1002/mpr.1571

Fried, E. I., Bockting, C., Arjadi, R., Borsboom, D., Amshoff, M. Cramer, A. O., . . Stroebe, M. (2015). From loss to loneliness: The relationship between bereavement and depressive symptoms. Journal of Abnormal Psychology, 124, 256-265. doi:10.1037/abn0000028

Gillies, J., \& Neimeyer, R. A. (2006). Loss, grief, and the search for significance: Toward a model of meaning reconstruction in bereavement. Journal of Constructivist Psychology, 19, 31-65. doi:10.1080/10720530500311182

Golden, A. M. J., \& Dalgleish, T. (2010). Is prolonged grief distinct from bereavement-related posttraumatic stress? Psychiatry Research, 178, 336-341. doi:10.1016/i.psychres.2009.08.021

Granek, L., \& Peleg-Sagy, T. (2017). The use of pathological grief outcomes in bereavement studies on African Americans. Transcultural Psychiatry, 54, 384-399. doi:10.1177/1363461517708121

Han, D. H., Lee, J. J., Moon, D. S., Cha, M. J., Kim, M. A., Min, S., . . Chung, U. S. (2016). Korean version of Inventory of Complicated Grief Scale: Psychometric properties in Korean adolescents. Journal of Korean Medical Science, 31, 114-119. doi:10.3346/jkms.2016.31.1.114

Holland, J. M., Currier, J. M., Coleman, R. A., \& Neimeyer, R. A. (2010). The Integration of Stressful Life Experiences Scale (ISLES): Development and initial validation of a new measure. International Journal of Stress Management, 17, 325-352. doi:10.1037/a0020892

Holland, J. M., Currier, J. M., \& Neimeyer, R. A. (2014). Validation of the Integration of Stressful Life Experiences Scale-short form in a bereaved sample. Death Studies, 38, 234-238. doi:10.1080/07481187.2013.829369

Horn, J. L. (1965). A rationale and test for the number of factors 
in factor analysis. Psychometrika, 30, 179-185.

doi: $\underline{10.1007 / b f 02289447}$

Kersting, A., Brahler, E., Glaesmer, H., \& Wagner, B. (2011).

Prevalence of complicated grief in a representative populationbased sample. Journal of Affective Disorders, 131, 339-343.

doi:10.1016/j.jad.2010.11.032

Klinitzke, G., Domschke, K., Wagner, B., Klauke, B., \& Kersting, A. (2014). Verlusterleben und prolongierte Trauer bei depressiven Patienten. [Experience of loss and complicated grief in depressive inpatients]. Psychiatrische Praxis, 41, 313-318. doi:10.1055/s-0033-1349467

Kristensen, P., Weisæth, L., \& Heir, T. (2012). Bereavement and mental health after sudden and violent losses: A review. Psychiatry: Interpersonal and Biological Processes, 75, 76-97. doi: $\underline{10.1521 / p s y c .2012 .75 .1 .76}$

Kristensen, P., Weisæth, L., Hussain, A., \& Heir, T. (2015). Prevalence of psychiatric disorders and functional impairment after loss of a family member: A longitudinal study after the 2004 tsunami. Depression and Anxiety, 32, 49-56.

doi: $\underline{10.1002 / d a .22269}$

Latham, A. E., \& Prigerson, H. G. (2004). Suicidality and bereavement: Complicated grief as psychiatric disorder presenting greatest risk for suicidality. Suicide and LifeThreatening Behavior, 34, 350-362. doi:10.1521/suli.34.4.350.53737

Li, J., Chow, A. Y. M., Shi, Z. B., \& Chan, C. L. W. (2015). Prevalence and risk factors of complicated grief among Sichuan earthquake survivors. Journal of Affective Disorders, 175, 218-223. doi:10.1016/j.jad.2015.01.003

Lumbeck, G., Brandstatter, M., \& Geissner, E. (2012).

Preliminary validation of the German version of the Inventory of Complicated Grief (ICG-D). Zeitschrift für Klinische Psychologie und Psychotherapie, 41, 243-248. doi:10.1026/1616-3443 $\underline{\text { la000172 }}$

Lundorff, M., Holmgren, H., Zachariae, R., Farver-Vestergaard, I., \& O'Connor, M. (2017). Prevalence of prolonged grief disorder in adult bereavement: A systematic review and metaanalysis. Journal of Affective Disorders, 212, 138-149. 
doi:10.1016/j.jad.2017.01.030

Maercker, A., Brewin, C. R., Bryant, R. A., Cloitre, M., Reed, G. M., van Ommeren, M., ... Saxena, S. (2013). Proposals for mental disorders specifically associated with stress in the International Classification of Diseases-11. The Lancet, 381, 1683-1685. doi:10.1016/S0140-6736(12)62191-6

Masferrer, L., Garre-Olmo, J., \& Caparros, B. (2017). Factor structure and concurrent construct validity of ICG among bereaved substance users. Actas Espanolas de Psiquiatria, 45, 47-55.

Mundt, J. C., Marks, I. M., Shear, M. K., \& Greist, J. H. (2002). The Work and Social Adjustment Scale: A simple measure of impairment in functioning. British Journal of Psychiatry, 180, 461-464. doi:10.1192/bjp.180.5.461

Muthén, L. K., \& Muthén, B. O. (1998-2012). Mplus User's Guide. Seventh Edition. Los Angeles, CA: Muthén \& Muthén.

Neimeyer, R. A. (2017). Complicated grief: Assessment and intervention. In S. N. Gold (Ed.), APA Handbook of Trauma Psychology: Trauma Practice, Vol. 2 (pp. 343-362).

Washington: American Psychological Association.

Neimeyer, R. A., Hogan, N. S., \& Laurie, A. (2008). The measurement of grief: Psychometric considerations in the assessment of reactions to bereavement. In M. S. Stroebe, R. O. Hansson, H. Schut, \& W. Stroebe (Eds.), Handbook of Bereavement Research and Practice: Advances in Theory and Intervention (pp. 133-161). Washington: American Psychological Association.

Newson, R. S., Boelen, P. A., Hek, K., Hofman, A., \& Tiemeier, H. (2011). The prevalence and characteristics of complicated grief in older adults. Journal of Affective Disorders, 132, 231-238. doi:10.1016/j.jad.2011.02.021

Nickerson, A., Liddell, B. J., Maccallum, F., Steel, Z., Silove, D., \& Bryant, R. A. (2014). Posttraumatic stress disorder and prolonged grief in refugees exposed to trauma and loss. BMC Psychiatry, 14. doi:10.1186/1471-244x-14-106

O'Connor, B. P. (2000). SPSS and SAS programs for determining the number of components using parallel analysis 
and Velicer's MAP test. Behavior Research Methods,

Instruments, \& Computers, 32, 396-402.

doi: $\underline{10.3758 / \mathrm{BF} 03200807}$

Pedersen, G., Kvarstein, E. H., \& Wilberg, T. (2017). The Work and Social Adjustment Scale: Psychometric properties and validity among males and females, and outpatients with and without personality disorders. Personality and Mental Health, 11, 215-228. doi: $10.1002 / p m h .1382$

Prigerson, H. G., Frank, E., Kasl, S. V., Reynolds III, C. F., Anderson, B., Zubenko, G. S., . . Kupfer, D. J. (1995). Complicated grief and bereavement-related depression as distinct disorders: Preliminary empirical validation in elderly bereaved spouses. American Journal of Psychiatry, 152, 22-30. doi:10.1176/ajp.152.1.22

Prigerson, H. G., Horowitz, M. J., Jacobs, S. C., Parkes, C. M., Aslan, M., Goodkin, K., . . Maciejewski, P. K. (2009). Prolonged grief disorder: Psychometric validation of criteria proposed for DSM-V and ICD-11. PLOS Medicine, 6(8), e1000121. doi:10.1371/journal.pmed.1000121

Prigerson, H. G., Maciejewski, P. K., Reynolds III, C. F., Bierhals, A. J., Newsom, J. T., Fasiczka, A., . . Miller, M. (1995). Inventory of Complicated Grief: A scale to measure maladaptive symptoms of loss. Psychiatry Research, 59, 65-79. doi:10.1016/0165-1781(95)02757-2

Reise, S. P., Bonifay, W. E., \& Haviland, M. G. (2013). Scoring and modeling psychological measures in the presence of multidimensionality. Journal of Personality Assessment, 95, 129-140. doi:10.1080/00223891.2012.725437

Revelle, W. (2017). psych: Procedures for Personality and Psychological Research. https://CRAN.R-project.org /package $=$ psych Version $=1.7 .5$.

Rosenblatt, P. C. (2008). Grief across cultures: A review and research agenda. In M. S. Stroebe, R. O. Hansson, H. Schut, \& W. Stroebe (Eds.), Handbook of bereavement research and practice: Advances in theory and intervention (pp. 207-222). Washington: American Psychological Association.

Schmitt, T. A., \& Sass, D. A. (2011). Rotation criteria and hypothesis testing for exploratory factor analysis: Implications 
for factor pattern loadings and interfactor correlations.

Educational and Psychological Measurement, 71, 95-113. doi: $\underline{10.1177 / 0013164410387348}$

Shear, M. K. (2015). Complicated grief. New England Journal of Medicine, 372, 153-160. doi:10.1056/NEJMcp1315618

Shear, K., Frank, E., Houck, P. R., \& Reynolds, C. F. (2005). Treatment of complicated grief: A randomized controlled trial. JAMA: Journal of the American Medical Association, 293, 2601-2608. doi:10.1001/jama.293.21.2601

Shear, M. K., Simon, N., Wall, M., Zisook, S., Neimeyer, R., Duan, N., . . Keshaviah, A. (2011). Complicated grief and related bereavement issues for DSM-5. Depression and Anxiety, 28, 103-117. doi:10.1002/da.20780

Shear, M. K., Wang, Y. J., Skritskaya, N., Duan, N. H., Mauro, C., \& Ghesquiere, A. (2014). Treatment of complicated grief in elderly persons: A randomized clinical trial. JAMA Psychiatry, 71, 1287-1295. doi:10.1001/jamapsychiatry.2014.1242

Simon, N. M., Shear, K. M., Thompson, E. H., Zalta, A. K., Perlman, C., Reynolds, C. F., . . Silowash, R. (2007). The prevalence and correlates of psychiatric comorbidity in individuals with complicated grief. Comprehensive Psychiatry, 48, 395-399. doi:10.1016/j.comppsych.2007.05.002

Simon, N. M., Wall, M. M., Keshaviah, A., Dryman, M. T., LeBlanc, N. J., \& Shear, M. K. (2011). Informing the symptom profile of complicated grief. Depression and Anxiety, 28, 118-126. doi:10.1002/da.20775

Silove, D., Ventevogel, P., \& Rees, S. (2017). The contemporary refugee crisis: An overview of mental health challenges. World Psychiatry, 16, 130-139.

doi: $10.1002 /$ wps. 20438

Stroebe, M., Stroebe, W., \& Schut, H. (2001). Gender differences in adjustment to bereavement: An empirical and theoretical review. Review of General Psychology, 5, 62-83. doi:10.1037/1089-2680.5.1.62

Thimm, J. C., \& Holland, J. M. (2017). Early maladaptive schemas, meaning making, and complicated grief symptoms after bereavement. International Journal of Stress 
Yong, A. G., \& Pearce, S. (2013). A beginner's guide to factor analysis: Focusing on exploratory factor analysis. Tutorials in Quantitative Methods for Psychology, 9, 79-94.

Zetumer, S., Young, I., Shear, M. K., Skritskaya, N., Lebowitz, B., Simon, N., . . Z Zisook, S. (2015). The impact of losing a child on the clinical presentation of complicated grief. Journal of Affective Disorders, 170, 15-21. doi:10.1016/j.jad.2014.08.021

Citation

Thimm, J. C., Davidsen, M., Elsness, M. M., \& Vara, H. (2019). Reliability, factor structure, and validity of the Inventory of Complicated Grief (ICG) in a general bereaved sample in Norway. Scandinavian Psychologist, 6, e7. https://doi.org /10.15714/scandpsychol.6.e7

Abstract

Reliability, factor structure, and validity of the Inventory of Complicated Grief (ICG) in a general bereaved sample in Norway

The Inventory of Complicated Grief (ICG) is the most widely used instrument to assess the severity of prolonged grief reactions after the loss of a loved one. The purpose of the present study was to investigate the psychometric properties of the Norwegian ICG by examining its reliability, factor structure, and relationships with the anxiety and depression subscales of the Brief Symptom Inventory, the Integration of Stressful Life Events Scale - Short Form, and the Work and Social Adjustment Scale. The results showed that the Norwegian ICG has high reliability $\left(\omega_{t}=.95\right)$. Exploratory factor analysis yielded three factors (disbelief/bitterness, detachment, yearning/hallucinations) that align with factors found in previous investigations. With regard to external validity, moderate to high correlations with symptoms of anxiety and depression, difficulties with integration of the loss, and functional impairment were found. The results support the use of the ICG in bereaved populations in Norway.

Keywords: bereavement, complicated grief, factor analysis, Inventory of Complicated Grief, validity, reliability.

Author affiliations: Jens C. Thimm, Maylinn Davidsen, Mie M. 
Elsness \& Helga Vara - Department of Psychology, UiT The Arctic University of Norway, Troms $\varnothing$, Norway.

Contact information: Jens C. Thimm, Department of Psychology, University of Tromsø, Norway, PO Box 6050 Langnes, 9037 Tromsø, Norway. Email: icthimm@gmail.com.

Received: July 2, 2018. Accepted: March 14, 2019.

Published: May 29, 2019.

Language: English.

Competing interests: The authors report no conflict of interest. The authors alone are responsible for the contents and writing of this paper.

This is a peer-reviewed paper. 